\title{
Elisabetta Longhi, Il "Traité des excitants modernes" di Honoré de Balzac, in Percorsi di mistica laica fra Ottocento e Novecento. Balzac, Baudelaire, Benjamin
}

\section{Marco Stupazzoni}

\section{(2) OpenEdition \\ Journals}

Edizione digitale

URL: http://journals.openedition.org/studifrancesi/6330

DOI: $10.4000 /$ studifrancesi.6330

ISSN: 2421-5856

\section{Editore}

Rosenberg \& Sellier

\section{Edizione cartacea}

Data di pubblicazione: 1 novembre 2010

Paginazione: 564

ISSN: 0039-2944

\section{Notizia bibliografica digitale}

Marco Stupazzoni, «Elisabetta Longhi, II "Traité des excitants modernes" di Honoré de Balzac, in Percorsi di mistica laica fra Ottocento e Novecento. Balzac, Baudelaire, Benjamin», Studi Francesi [Online], 162 (LIV I III) | 2010, online dal 30 novembre 2015, consultato il 10 janvier 2021. URL: http://

journals.openedition.org/studifrancesi/6330 ; DOI: https://doi.org/10.4000/studifrancesi.6330

Questo documento è stato generato automaticamente il 10 janvier 2021.

\section{cc) (†) $\odot$}

Studi Francesi è distribuita con Licenza Creative Commons Attribuzione - Non commerciale - Non opere derivate 4.0 Internazionale. 


\title{
Elisabetta Longhi, Il "Traité des excitants modernes" di Honoré de Balzac, in Percorsi di mistica laica fra Ottocento e Novecento. Balzac, Baudelaire, Benjamin
}

\author{
Marco Stupazzoni
}

\section{NOTIZIA}

elisabetTA LONGHI, Il “Traité des excitants modernes" di Honoré de Balzac, in Percorsi di mistica laica fra Ottocento e Novecento. Balzac, Baudelaire, Benjamin, Parma, Monte Università Parma, «L'eredità di Babele», 2007, pp. 13-30.

1 Il Traité des excitants modernes (1838) di Balzac è analizzato con acume dall'autrice in questo capitolo che forma il primo contributo di una trilogia di studî a carattere interdisciplinare centrato sui legami non certo semplici ed immediati di tre letterati e filosofi con la modernità del proprio tempo.

Il Traité è un'opera di vasta portata in relazione non solo al sistema di pensiero balzachiano, sempre teso a porre in primo piano lo studio dei rapporti tra spirito e materia, ma anche al particolare contesto sociologico, politico, economico e scientifico del primo Ottocento. Quest'opera fa parte della Pathologie de la vie sociale assieme al Traité de la vie élégante e alla Théorie de la démarche, ma, a differenza di questi ultimi due testi (pubblicati rispettivamente nel 1830 e nel 1833), il Traité costituisce una vera e propria denuncia della degenerazione patologica della civiltà e delle sue malattie sociali causate dall'uso smoderato dei cosiddetti "eccitanti moderni“, quali l'alcool e il tabacco. In queste riflessioni, che denotano l'influenza diretta di Rousseau, emerge «il senso di degradazione della società» (p. 18) e della vita parigina, in particolare, moderne a cui 
Balzac si accosta con profondo pessimismo, non riuscendo tuttavia, anch'egli, a sfuggire,abusando di caffè per tutto il corso della sua intensa esistenza di forzato della penna, alla trasgressione di quelle regole e di quei principî che erano i fondamenti della sua "macrobiotica". 